abrasion in service. It is now usual to remove scale by pickling, by weathering, or by some other suitable method, prior to painting, in order to avoid such disaster.

A second method of combating corrosion consists in alloying the iron with some other element that will render it incorrodible. This is the principle underlying the so-called "stainless steel," which contains some 12 to 14 per cent. of chromium, and is remarkably resistant to neutral corrosion, although acids dissolve it with ease. Unfortunately the cost is high, but once that difficulty is surmounted, a vast future lies in store for stainless metals. To realise this it is not essential that the price should fall to that of an ordinary carbon steel. To the writer's own knowledge the cost of painting the steel work in a certain large works recently averaged nearly $5 l$. per ton of steel painted. Assuming the paint will not require renewal within five years, the average annual cost is still $\mathrm{I} l$. per ton of steel. A firm could thus clearly afford to pay considerably extra in initial outlay if by so doing a really incorrodible structure could be obtained which would not require subsequent periodic treatment.

Yet a third method of reducing wastage by corrosion has been investigated, namely, the removal of the active corroding agent, dissolved oxygen, from waters in contact with the metal. The various means of doing this are discussed by Mr. Frank N. Speller ${ }^{1}$ in an interesting paper entitled "Control of Corrosion by Deactivation of Water." The method has its limitations, but for hot-water heating systems it would appear to be particularly suitable. The oxygen may be removed either chemically or by purely physical means. A 1 Journ, Franklin Institute, April 1922. satisfactory plant was erected in Pittsburgh in ror 5 in which the water is first made to flow through a "deactivator" which is a tank filled with a special type of expanded steel lathing. The steel rusts and thus deoxygenates the water, which then passes on to the heating system and is now non-corrosive. The principle is simple enough, but in practice it is necessary to pay great attention to the manner in which the deactivator is charged. Miscellaneous steel turnings usually rust together into a tight mass which offers serious resistance to the flow of the water. In a later form of deactivator installed in Boston in I9I 7 a filter was provided in order to remove all suspended hydroxide of iron.

Many types of mechanical de-aerators have been designed. The apparatus made by "Balke" in Germany appears to have given satisfactory results. The water at ordinary temperature is sprayed into a chamber carrying a 90 per cent. vacuum, and the released gases are pumped off into a condenser. The efficiency of mechanical de-aerators is of course limited by the solubility of the gases, the temperature, and the power of the vacuum. Normally, therefore, there will always remain a certain amount of unextracted oxygen which may be sufficient to induce gradually serious corrosion in the plant. On the other hand, chemical processes can remove all the dissolved oxygen under favourable conditions. Speller therefore suggests that where very large volumes of water require de-aeration, an economical type of apparatus would be one in which the bulk of the dissolved oxygen is first removed by some simple form of mechanical de-aerator, and the residual oxygen, say the last 5-ro per cent., by chemical treatment.

\title{
Obituary.
}

\section{ERNeSt Solvay.}

$\mathrm{O}^{\mathrm{N}}$ $\mathrm{N}$ May 26 last, at the ripe age of eighty-five, there passed away, at his residence in Brussels, in the person of Ernest Solvay, one of the world's greatest industrial chemists. To Nicolas Leblanc belongs the credit of inventing the first successful process for manufacturing artificial soda; but it remained for the brothers Ernest and Alfred Solvay to provide the world with a pure and cheap product.

Ernest Solvay was born at Rebecq in Brabant, Belgium, on April 16, 1838. He was the son of Alexandre Solvay, a quarry proprietor and salt refiner. In 1838 two English chemists, Harrison Gray Dyar and John Hemming, patented a process for producing carbonate of soda by acting upon sodium chloride with ammonium bicarbonate and producing sodium bicarbonate and ammonium chloride. The sodium bicarbonate upon calcination yielded soda ash, and the ammonium chloride was decomposed by lime to free the ammonia for re-use. The patentees themselves, and several well-known chemists, erected works to manufacture by this process, but all proved failures, principally on account of the high loss of ammonia. The young Belgian chemist, Ernest Solvay, at the age of twenty-four, was attracted by the process, and, after two years of study and experiment, he devised such modifications as appeared to him to ensure its practicability, and embodied them in a patent in I863.

Calling to his aid his brother Alfred, who had been trained for a commercial career at Antwerp and at Hull, they erected works at Couillet, near Brussels, as Solvay et Cie, with a capital of 5440l. With the starting of these works in 1865 the brothers met with most of the troubles and disasters that had daunted the earlier experimenters. Their experience is perhaps best described in Ernest Solvay's own words :

"With the starting of the works in 1865 began the everlasting struggle, the incessant need for improvements in apparatus, and the series of accidents inseparable from every new industry. This was the hill of Calvary which we had to climb, and its rough road might perhaps have stopped me if I had not been sustained by my confidence of success in the task that had to be accomplished, and above all by that devoted helper, my brother Alfred."

In the following year (I866) the works were producing only $\mathrm{I}^{\frac{1}{2}}$ tons of soda ash per day, but by 1869 the process had proved so successful that the works were doubled in size. During these fateful four years, Solvay had encountered all the difficulties that had baffled his predecessors, both technical and financial; but, by his application of wonderful scientific skill and his tireless attention to work, he succeeded in evolving

NO. 2750 , vOL. I IO] 
a remunerative process of manufacture. It was, however, far from perfect, and for the next fifty years Solvay ever strove to reach perfection, sparing neither time nor money to make it approach the ideal. At the time of his death, there are very few methods of manufacture that have so nearly reached the ideal as the Ammonia Soda process.

In 1873 Solvay granted a licence to John Brunner and Ludwig Mond to work the process in England, and Brunner, Mond and Co. started works at Winnington, Northwich, in that year. From this business connexion there sprang up a friendship among the three men that lasted as long as their lives, and it is difficult to decide whether Solvay or Mond effected thereafter the greater number of improvements in the process and apparatus.

In the same year Solvay and Co. erected their large works at Dombasle near Nancy, introducing all such improvements in plant as experience at Couillet had shown to be advisable.

From this time onwards to I9I4 few years passed without some new works being erected to carry on the manufacture ; in the United States in $188 \mathrm{I}$, in Russia in $\mathrm{r} 88 \mathrm{r}$, in Germany and Austria in 1885 , and later in Hungary, Spain, Italy, and Canada, until in I9r4 there were scattered throughout the world twentythree separate works engaged in the Solvay Ammonia Soda process, which were capable of producing nearly 2,000,000 tons of soda ash per year.

With the growth of the Ammonia Soda process, the production of alkali by the Leblanc method gradually declined, until it reached the point where it had to depend upon its chlorine products for its continued survival, and of late years even this monopoly has been seriously challenged by the electrolytic processes. In I863 the world's production of soda, by the Leblanc process, was 300,000 tons a year. In I9I3, the total production amounted to nearly 3,000,000 tons, of which almost two-thirds was made by the Solvay process, while the sale price had dropped to onequarter. The essential raw materials for the Solvay process are salt, limestone, coke, coal, and ammonia, and in selecting sites for new works, Solvay was ever careful to choose them as near as possible to the source of supply of some of these.

In seeking for a cheap and plentiful supply of ammonia, Solvay was led to study the production of coke, and eventually, in conjunction with Mr. SemetSolvay, he designed a bye-product coke oven which yielded ammonia through the scrubbing of the gas before its combustion for heating purposes. Many thousands of these Semet-Solvay ovens have been built in Belgium, France, England, Germany, the United States, Italy, and Japan, and in $\mathrm{rg}^{\mathrm{I}} 3$ they were producing about ro million tons of coke a year.

In the midst of his immense industrial activities Solvay was ever mindful of the welfare of his employees. Working a process that must of necessity be continuous, he was one of the first to reduce the hours of labour from I2 to 8-hour shifts. He insured his workmen against accidents, instituted savings-banks and retiring allowances, provided them with medical attention, built houses for them, and remitted the rent in cases of long service or distress, made free grants of land for culture, built schools and gave scholarships, and made grants in aid of higher education both in Belgium and abroad.

On the occasion of the company's fiftieth anniversary, a number of grants were made, among which were: 200,000 francs to the Université du Travail, Charleroi, 500,000 francs to provide prizes every fourth year for work on such contagious diseases as the poor are specially liable to suffer from, 500,000 francs to the University of Paris towards the Institute of Applied Chemistry, 500,000 francs to the University of Nancy to complete the Electrical Institute and found a chair of electro-chemistry. In addition, their workpeople received substantial concessions and bonuses. Ernest Solvay's sympathies and interests were not confined to his own workpeople, for he was absorbingly interested in the intellectual and social advancement of mankind in general. He published not only many treatises on these subjects, but also from his immense wealth financed or created numerous institutions for their study; e.g. the Solvay Society of Brussels and institutes of chemistry, physics, physiology, and sociology. In order to encourage the development of chemical and physical science, by providing funds for research workers and by holding conferences, he also inaugurated the Solvay International Institutes of Chemistry and of Physics, and endowed each with a capital of $x, 000,000$ francs.

During the war, Solvay elected to remain in Brussels in order that he might alleviate the suffering which he foresaw would be the lot of the poor. He devoted his energies and his fortune to this object throughout the whole of the German occupation, and the city will never forget his beneficence. Upon his return to the capital, King Albert personally expressed his thanks to him and created him a Minister of State. He was also the recipient of many other honours. He was a Grand Commander of the Order of Leopold, a Chevalier of the Legion of Honour, a Doctor of the University of Brussels, an honorary member of the Royal Institution of London, and of the German, French, American, and Dutch Chemical Societies, and a corresponding member of the French Academy of Sciences.

At the celebration of the fiftieth anniversary of the formation of his company, he was presented by Prof. Haller in the name of the French Institute with the gold Lavoisier Medal, and by Prof. Appell with the medal of the University of Paris.

In private life Ernest Solvay's tastes were simple, and he was ever happiest in his own family circle. $\mathrm{He}$ attracted to his side many men of exceptional ability and formed lasting friendships. By nature he was generally optimistic, and he had a very keen sense of humour. He was an ardent mountaineer, and regularly his summer holidays were spent among the Alps. He could climb vigorously at the age of seventy-five, and abandoned the sport only a few years prior to his death.

The Hon. V. A. H. H. Onslow.

Huia OnsLow, son of the fourth Earl of Onslow, was born in New Zealand in 1890 , where his father was Governor-General. Educated at Eton and Trinity College, Cambridge, he met with a calamitous accident at the close of his University career : an injury received in diving left him paralysed below the waist, with no 